OPEN ACCESS

Edited by:

Xun Suo,

China Agricultural University,

China

Reviewed by:

Dolores Correa,

Instituto Nacional de

Pediatria, Mexico

Dina Weilhammer,

United States Department of

Energy (DOE), United States

*Correspondence:

Nian-Zhang Zhang zhangnianzhang@caas.cn;

Xing-Quan Zhu

xingquanzhu1@hotmail.com

Specialty section: This article was submitted to

Microbial Immunology,

a section of the journal

Frontiers in Immunology

Received: 24 February 2018 Accepted: 18 June 2018

Published: 29 June 2018

Citation:

Zhang $N-Z$, Gao Q, Wang $M$, Elsheikha HM, Wang B, Wang J-L, Zhang F-K, Hu L-Y and Zhu X-Q (2018) Immunization With a DNA Vaccine Cocktail Encoding TgPF, TgROP16, TgROP18, TgMIC6, and TgCDPK3 Genes Protects Mice Against Chronic Toxoplasmosis.

Front. Immunol. 9:1505. doi: 10.3389/fimmu.2018.01505

\section{Immunization With a DNA Vaccine Cocktail Encoding TgPF, TgROP16, TgROP18, TgMIC6, and TgCDPK3 Genes Protects Mice Against Chronic Toxoplasmosis}

\author{
Nian-Zhang Zhang ${ }^{1 *}$, Qi Gao ${ }^{1,2}$, Meng Wang ${ }^{1}$, Hany M. Elsheikha ${ }^{3}$, Bo Wang ${ }^{4}$, \\ Jin-Lei Wang ${ }^{1}$, Fu-Kai Zhang ${ }^{1}$, Ling-Ying Hu' and Xing-Quan Zhu ${ }^{1,5 *}$
}

'State Key Laboratory of Veterinary Etiological Biology, Key Laboratory of Veterinary Parasitology of Gansu Province, Lanzhou Veterinary Research Institute, Chinese Academy of Agricultural Sciences, Lanzhou, China, ${ }^{2}$ Hunan Entry-Exit Inspection and Quarantine Bureau, Changsha, China, ${ }^{3}$ Faculty of Medicine and Health Sciences, School of Veterinary Medicine and Science, University of Nottingham, Loughborough, United Kingdom, ${ }^{4}$ Department of Mathematics, University of Leicester, Leicester, United Kingdom, ${ }^{5}$ Jiangsu Co-Innovation Center for the Prevention and Control of Important Animal Infectious Diseases and Zoonoses, Yangzhou University College of Veterinary Medicine, Yangzhou, China

Toxoplasmosis is a zoonotic disease caused by the intracellular protozoan Toxoplasma gondii; and a major source of infection in humans is via ingestion of $T$. gondii tissue cysts. Ultimately, the goal of anti-toxoplasmosis vaccines is to elicit a sustainable immune response, capable of preventing formation of the parasite tissue cysts - or, at least, to restrain its growth. In this study, we formulated a cocktail DNA vaccine and investigated its immunologic efficacy as a protection against the establishment of $T$. gondii cysts in the mouse brain. This multicomponent DNA vaccine, encoded the TgPF, TgROP16, TgROP18, TgMIC6, and TgCDPK3 genes, which play key roles in the pathogenesis of T. gondii infection. Results showed that mice immunized via intramuscular injection three times, at 2-week intervals with this multicomponent DNA vaccine, mounted a strong humoral and cellular immune response, indicated by significantly high levels of total lgG, $\mathrm{CD}^{+}$and $\mathrm{CD}^{+} \mathrm{T}$ lymphocytes, and antigen-specific lymphocyte proliferation when compared with non-immunized mice. Immunization also induced a mixed Th1/Th2 response, with a slightly elevated lgG2a to IgG1 ratio. The increased production of proinflammatory cytokines gamma-interferon, interleukin-2, and interleukin-12 $(p<0.0001)$ correlated with increased expression of p65/RelA and T-bet genes of the NF-kB pathway. However, no significant difference was detected in level of interleukin-4 ( $p>0.05)$. The number of brain cysts in immunized mice was significantly less than those in non-immunized mice $(643.33 \pm 89.63$ versus $3,244.33 \pm 96.42, p<0.0001)$, resulting in an $80.22 \%$ reduction in the parasite cyst burden. These findings indicate that a multicomponent DNA vaccine, encoding TgPF, TgROP16, TgROP18, TgMIC6, and TgCDPK3 genes, shows promise as an immunization strategy against chronic toxoplasmosis in mice, and calls for a further evaluation in food-producing animals.

Keywords: Toxoplasma gondii, chronic toxoplasmosis, cocktail DNA vaccine, multistage antigens, mixed Th1/Th2 immune response 


\section{INTRODUCTION}

Toxoplasma gondii, the causative agent of toxoplasmosis, infects nearly all warm-blooded vertebrates, including birds and humans $(1,2)$. Toxoplasmosis in immunocompetent people usually manifests as a flu-like, self-limiting infection; however, in immunocompromised patients (cancer, AIDS, and organ transplant recipients), reactivation of chronic toxoplasmosis can cause fatal complications, such as toxoplasmic encephalitis $(3,4)$. The reactivation of tissue cysts is manifested by their rupture, followed by the conversion of released bradyzoites to tachyzoites, and a proliferation of tachyzoites. Therefore, the removal of $T$. gondii tissue cysts from infected individuals would prevent such reactivation. Tissue cysts of T. gondii in animals also present a potential threat to human health if they are consumed in raw or undercooked meat $(5,6)$. Currently, there are no available drugs to eliminate T. gondii tissue cysts $(7,8)$. It is therefore imperative that new approaches are developed for immunotherapy against this infection.

Development of vaccines to prevent T. gondii tissue cyst formation can be an effective approach to ensure the safety of meat products, originating from food-producing animals under backyard and free-ranging conditions $(9,10)$. Over the last two decades, various anti- $T$. gondii vaccine approaches have been evaluated in animal models. Previous studies have shown that DNA vaccine can induce, through enhanced humoral and cellular immune responses, immune protection against acute and chronic toxoplasmosis in animal models (11-15). Additional advantages of the DNA vaccination, when compared with using live-type vaccines, are their thermal stability, safety, and the low cost of production $(12,14)$. To date, no single DNA vaccine has provided full protection against $T$. gondii cyst formation $(9,16,17)$.

Toxoplasma gondii-specific cytotoxic T lymphocytes (CTLs) induced by immunization can improve the protective immunity against parasite infection $(9,14)$. Previous studies have shown that a multicomponent vaccine may offer better protection than a single antigen (16-19) due to the elevated numbers of T. gondiispecific CTLs, and the subsequent increase in the production of antigen-specific cytokine gamma-interferon (IFN- $\gamma)(19,20)$. A combination of different antigens, in theory, contain more CTL epitopes and are considered superior to a single antigen for protecting the host against $T$. gondii infection $(14,21)$.

This study aimed to examine the protective efficacy of a DNA multicomponent vaccine against chronic T. gondii infection. Five well-characterized antigens play key roles in host-parasite interaction including host cell attachment (MIC6) (22), gliding motility and invasion (profilin) $(23,24)$, signal transduction and egress (calcium-dependent protein kinase 3; CDPK3) (25), intracellular proliferation (ROP18) (26), and modulation of host gene expression (ROP16) (27). These antigens were selected to formulate a cocktail DNA vaccine. We investigated the immunologic efficacy of this vaccine, in protecting Kunming mice against chronic $T$. gondii infection. In addition, we conducted a longitudinal immune analysis and evaluated several immunization strategies, in order to provide some guidance for optimal schedules of vaccine administration in future clinical trials.
Utilization of the DNA vaccine with multi-antigens is a step forward in the development of commercial vaccine formulations against chronic toxoplasmosis for use in humans and food-producing animals.

\section{MATERIALS AND METHODS}

\section{Ethics Statement}

Animal experiments were reviewed and approved by the Animal Administration and Ethics Committee of Lanzhou Veterinary Research Institute, Chinese Academy of Agricultural Sciences. The study was performed in strict compliance with the recommendations set forth in the Animal Ethics Procedures and Guidelines of the People's Republic of China. All efforts were made to minimize animal suffering and to reduce the numbers of animals used in the experiments.

\section{Mice and Parasite Strain}

Specific pathogen-free female Kunming mice, aged 6-8 weeks, were purchased from the Center of Laboratory Animals, Lanzhou Institute of Biological Products, Lanzhou, China. They were housed, in pathogen-free conditions, at Lanzhou Veterinary Research Institute in controlled room under stable conditions (12-h/12-h dark/light cycle, $50-60 \%$ humidity, and $~ 22^{\circ} \mathrm{C}$ temperature). Mice had access to sterilized food and water ad libitum and were acclimated for 1 week before use. The avirulent T. gondii type II Prugniuad (Pru) was propagated in our laboratory, by oral passage of infected brain homogenates in Kunming mice (28). Bradyzoites of T. gondii Pru strain were used to prepare the T. gondii lysate antigen (TLA) as described previously $(29,30)$.

\section{Preparation of Multicomponent DNA Vaccine}

The pVAX1 plasmids encoding T. gondii profilin (pVAX1-PF), rhoptry protein 16 (pVAX1-ROP16), rhoptry protein ROP18 (pVAX1-ROP18), microneme protein 6 (pVAX1-MIC6), and calcium-dependent protein kinase 3 (pVAX1-CDPK3) were constructed as previously reported (31-35), with the fidelity of all plasmids confirmed by sequencing (Sangon, China). The five eukaryotic plasmids were each transformed into $E$. coli $\mathrm{DH} 5 \alpha$ for propagation and were isolated by anion exchange chromatography (EndoFree Plasmid Giga Kit, Qiagen Sciences, MD, USA) following the manufacturer's instruction. Plasmid concentration and purity was determined by measuring the optical density ratio $A_{260} / A_{280}$. The purified plasmids were stored at $-20^{\circ} \mathrm{C}$ until used in the mouse immunization protocols.

\section{Immunization and Challenge}

Mice $(n=120)$ were randomly allocated to six groups of 20 mice. Mice in groups G1, G2, and G3 were immunized using plasmids encoding either five genes, four genes, or one gene, respectively. Further details of the various vaccination regimens are listed in Table 1. Mice received intramuscular (i.m.) injections of $100 \mu \mathrm{g}$ of plasmids in $100 \mu \mathrm{l}$ phosphate-buffered saline (PBS), into the tibialis anterior muscles using a $1-\mathrm{ml}$ insulin syringe with a $28-G$ needle. Three vaccinations at 2 -week intervals were 
TABLE 1 | Vaccination regimens used in this study.

\begin{tabular}{|c|c|c|c|c|}
\hline Group & Immunization protocol & Content & Volume & Administration \\
\hline G1 & pVAX1 plasmids expressing ROP16 + ROP18 + MIC6 + CDPK3 + PF & $20 \mu \mathrm{g} /$ plasmid & $100 \mu \mathrm{l}$ & Intramuscular \\
\hline G2 & pVAX1 plasmids expressing ROP16 + ROP18 + MIC6 + CDPK3 & $25 \mu \mathrm{g} /$ plasmid & $100 \mu \mathrm{l}$ & Intramuscular \\
\hline G3 & pVAX1-PF & $100 \mu \mathrm{g}$ & $100 \mu \mathrm{l}$ & Intramuscular \\
\hline G4 & pVAX1 & $100 \mu g$ & $100 \mu \mathrm{l}$ & Intramuscular \\
\hline G5 & Phosphate-buffered saline & - & $100 \mu \mathrm{l}$ & Intramuscular \\
\hline G6 & Healthy control & - & - & - \\
\hline
\end{tabular}

performed. Mice in G4 and G5 received empty pVAX1 vector and PBS, respectively. Mice in G6 were healthy untreated controls (non-immunized and uninfected). Following the primary immunization, mice in G1-G5 were provided with two booster immunizations at weeks 2 and 4 . For the challenge, 2 weeks after the final immunization ( 6 weeks post initial immunization), 6 mice from each group were inoculated orally with $200 \mu$ of PBS containing 10 tissue cysts of the avirulent T. gondii Pru strain. Control mice received $200 \mu \mathrm{l}$ of PBS without cysts. Six weeks post challenge, the mouse brains were removed, homogenized in $1 \mathrm{ml}$ of PBS and cysts were morphologically identified and counted under a microscope (40× objective) on three aliquots of $20 \mu \mathrm{l}$, without staining.

\section{Multicomponent DNA Vaccine Induced a Systemic Humoral Immune Response}

The blood samples from three mice in each group were collected from the tail vein pre-immunization, and 2 weeks after each of the three sequential immunizations (i.e., at 2, 4, and 6 weeks post immunization). The sera were separated by centrifugation of blood samples at 3,000 $\times g$ for $10 \mathrm{~min}$. Levels of anti-T. gondii, total IgG, and IgG isotypes (IgG2a and IgG1 antibodies, as markers for Th1 and Th2 responses) were examined in mice in each group using the SBA Clonotyping System-HRP Kit according to the manufacture's instruction (Southern Biotech Co., Ltd., Birmingham, AL, USA). Wells of 96-well microtiter plates were coated with $100 \mu \mathrm{l}(10 \mu \mathrm{g} / \mathrm{ml})$ TLA diluted in PBS at $4^{\circ} \mathrm{C}$ overnight, and then washed with PBST (PBS with $0.05 \%$ Tween-20). Plates were then treated with PBS-T plus $1 \%$ low fat milk for $1 \mathrm{~h}$ at ambient temperature, in order to block non-specific binding sites. After washing the wells three times with PBS, mouse serum samples (1:10 diluted with PBS) were added to the wells, and incubated at $37^{\circ} \mathrm{C}$ for $1 \mathrm{~h}$ followed by washing three times with PBST. The serum from non-immunized mice was used as a negative control. Horse radish peroxidase (HRP) conjugated anti-mouse IgG (1:500 diluted with PBS) and anti-mouse IgG1 or IgG2a (1:1,000 diluted with PBS) were added to the wells and incubated for $1 \mathrm{~h}$ at $37^{\circ} \mathrm{C}$. Wells were then washed five times with PBST, and streptavidin-horseradish peroxidase was added for $1 \mathrm{~h}$ at ambient temperature. TMB (3,3',5,5' -tetramethyl benzidine) in $200 \mu$ citrate-phosphate buffer $\left(0.05 \mathrm{M} \mathrm{Na}_{2} \mathrm{HPO}_{4}\right.$, $0.025 \mathrm{M}$ citric acid, $\mathrm{pH} 4.0$ ) and $2 \mathrm{mM} \mathrm{H}_{2} \mathrm{O}_{2}$ were added to monitor the peroxidase activity. The reaction was stopped after 30 min by adding $2 \mathrm{M} \mathrm{H}_{2} \mathrm{SO}_{4}$. Analysis of antibody responses was based on absorbance, measured at $450 \mathrm{~nm}$ using an ELISA plate reader (iMark microplate absorbance reader; Bio-Rad,
Hercules, CA, USA). All measurements were performed in triplicate.

\section{Lymphocyte Proliferation Assay}

Spleens from five mice in each group were aseptically collected, 2 weeks after the final/third booster immunization and were pushed through a fine nylon mesh. After removal of red blood cells, using erythrocyte lysis buffer (Sangon, China), the purified splenocytes were re-suspended in RPMI medium, supplemented with $10 \%$ fetal calf serum and $100 \mathrm{U} / \mathrm{ml}$ penicillin/ streptomycin. The number of purified splenic lymphocytes was determined, and cells were cultured at a concentration of $2 \times 10^{5}$ cells/well in 96-well flat-bottom microwell plates, in complete RPMI medium. Cell cultures were stimulated with TLA (10 or $5 \mu \mathrm{g} / \mathrm{ml}$ ) in three wells. RPMI media only (no antigen) and Concanavalin A (ConA; $5 \mu \mathrm{g} / \mathrm{ml}$; Sigma, St. Louis, MO, USA) were used as nonstimulated and positive controls, respectively. After 4 days at $37^{\circ} \mathrm{C}$ in a humidified $5 \% \mathrm{CO}_{2}$ incubator, the level of in vitro proliferative response was determined using the 3-(4,5-dimethylthiazol-2-yl)-5-(3-carboxymethoxyphenyl)2-(4-sulfophenyl)-2H-tetrazolium, inner salt (MTS) assay (Promega, USA). The OD values were measured using a microplate reader (iMark microplate absorbance reader; BioRad, Hercules, CA, USA) at $490 \mathrm{~nm}$. Data were expressed as stimulation index (SI), which was calculated as the ratio of mean $\mathrm{OD}_{590}$ values in immunized and control groups.

\section{Antigen-Specific T-Cell Proliferation}

The percentages of $\mathrm{CD}^{+}$and $\mathrm{CD} 8^{+} \mathrm{T}$ lymphocytes in the purified splenocytes were determined by flow cytometry. The specific antigen epitope of each T subclass was stained with phycoerythrinlabeled anti-mouse CD3 (eBioscience), allophycocyanin-labeled anti-mouse CD4 (eBioscience), and fluorescein isothiocyanatelabeled anti-mouse CD8 (eBioscience) antibodies. The cell suspension was then fixed with FACScan buffer (PBS containing $1 \%$ BSA and $0.1 \%$ sodium azide) and $2 \%$ paraformaldehyde. All samples were analyzed for their fluorescence profiles on a FACScan flow cytometer (BD Biosciences) using System II software (Coulter).

\section{Cytokines}

Splenocytes at a density of $2 \times 10^{5}$ cells/well were co-cultured with TLA and medium only (negative control). Culture supernatants were harvested at $24 \mathrm{~h}$ for quantification of interleukin-2 (IL-2) and IL- 4 and at $96 \mathrm{~h}$ for IFN- $\gamma$ and interleukin-12 (IL-12). The level of each cytokine was determined using commercial ELISA 
kits, according to the manufacturer's instructions (BioLegend, USA). The supernatants from each cell culture were pipetted into microplate wells followed by assay buffer A. Then, $100 \mu \mathrm{l}$ of the detection solution was added into each well. After washing the plate four times, avidin-HRP A solution and the substrate solution E were added sequentially. The reaction was stopped by adding $100 \mu \mathrm{l}$ of stop solution. The sensitivity limits for the assays were $4 \mathrm{pg} / \mathrm{ml}$ for IL-12 (p70), $20 \mathrm{pg} / \mathrm{ml}$ for IFN- $\gamma, 10 \mathrm{pg} / \mathrm{ml}$ for IL-4, and $50 \mathrm{pg} / \mathrm{ml}$ for IL-2. Optical absorbance was read at $450 \mathrm{~nm}$. This experiment was performed in triplicate.

We studied the expression of the two transcription factors, p65/RelA and T-bet of the NF- $\kappa$ B pathway, in an effort to establish their roles in mediating the increased production of $\mathrm{T}$ cell cytokine (e.g., IFN- $\gamma$ and IL-12). Total RNA from $10^{7}$ purified splenocytes of mice from G1 to G6 were extracted using Trizol reagent (Invitrogen, USA), as per the manufacturer's instructions. RNAs were dissolved in RNase-free $\mathrm{ddH}_{2} \mathrm{O}$ (TaKaRa, China) and reverse transcribed first-strand cDNAs were used as templates for real-time (RT)-PCR. The primers for amplification of RelA/ p65 and T-bet genes are listed in Table 2. $\beta$-Actin was used as a housekeeping reference gene. The SYBR Green qPCR SuperMix was purchased from Invitrogen (USA). RT-PCR was performed on ABI PRISM ${ }^{\circledR} 7500$ Sequence Detection System (Applied Biosystems). The amplification reactions were performed under the following conditions: $50^{\circ} \mathrm{C} 2 \mathrm{~min}, 95^{\circ} \mathrm{C} 2 \mathrm{~min}, 40$ cycles of $95^{\circ} \mathrm{C}$ for $15 \mathrm{~s}$, and $60^{\circ} \mathrm{C}$ for $32 \mathrm{~s}$. Melting curve analysis was carried out under the following conditions: $1 \mathrm{~min}$ at $95^{\circ} \mathrm{C}, 65^{\circ} \mathrm{C}$ for $2 \mathrm{~min}$, and progressive increase from 65 to $95^{\circ} \mathrm{C}$ to ensure that a single product was amplified in each reaction. All measurements were run in triplicate.

\section{Statistical Analysis}

Two-way ANOVA with matched data at different weeks was used to compare the total IgG antibody responses between the mouse groups. Tukey's multiple comparisons test was then employed to test the differences between each of the three vaccination groups, and each of the three control groups at each week. Oneway ANOVA and Tukey's multiple comparisons test were used for comparison in regards to the levels of IgG1 and IgG2a, and IgG2a/IgG1 ratio, proliferation of splenocytes, the numbers of $\mathrm{CD}^{+}{ }^{+} \mathrm{CD}^{+}{ }^{+} \mathrm{CD}^{+}$and $\mathrm{CD} 3^{+} \mathrm{CD}^{+}{ }^{+} \mathrm{CD} 4^{+} \mathrm{T}$ cells, cytokine production, and the numbers of brain cysts. Welch's $t$ test was used to compare the qPCR in the three genes (p65/RelA, T-bet, and $\beta$-actin) between the blank control group and mice in group 1 . Data are presented as mean $\pm \mathrm{SD}$. All analyses and graphs were performed using GraphPad Prism version 7.04 (San Diego,

TABLE 2 | Sequences of primers used for amplification of p65/RelA, T-bet, and $\beta$-actin genes.

\begin{tabular}{ll}
\hline Primer name & Sequence \\
\hline T-bet-F & 5'-GCCAGGGAACCGCTTATATG-3' \\
T-bet-R & 5'-TGGAGAGACTGCAGGACGAT-3' \\
RelA-F & 5'-GAACCAGGGTGTGTCCATGT-3' \\
RelA-R & $5^{\prime}$-TCCGCAATGGAGGAGAAGTC-3' \\
$\beta$-Actin-F & $5^{\prime}$-GCTTCTAGGCGGACTGTTAC-3' \\
$\beta-$-Actin-R & $5^{\prime}$-CCATGCCAATGTTGTCTCTT-3'
\end{tabular}

CA, USA). The level of significance was defined as ${ }^{\star} p \leq 0.05$, ${ }^{* *}$ $p \leq 0.01,{ }^{* *} p \leq 0.001$, and ${ }^{* * *} p \leq 0.0001$.

\section{RESULTS}

\section{Identification of Plasmids}

Five purified plasmids pVAX1-PF, pVAX1-ROP16, pVAX1ROP18, pVAX1-MIC6, and pVAX1-CDPK3 were confirmed by sequencing prior to use in the immunization experiment. Sequence alignment analysis showed that no base deletion or change was detected after alignment with the corresponding sequences in GenBank: accession numbers AY937257.1, DQ116422, AM075204, EF102772, and AJ488146.2.

\section{Kinetics of Humoral Immune Responses}

We characterized temporal changes in the humoral immune responses following immunization. Sera were available pretreatment, and at weeks 2,4 , and 6 post sequential immunizations from mice in all groups. Levels of total IgG and its subclasses (IgG2a and IgG1) from these time points were determined using ELISA. As shown in Figure 1, the IgG responses tended to increase with the increased number of immunizations, and with the increased number of plasmids used in immunization. Levels of IgG in mice in G1, G2, and G3 increased proportionally with time following immunization, and peaked at 2 weeks after the third/final booster immunization. Statistical analyses of the results (for weeks 0, 2, 4, and 6 post immunization) were performed using a two-way ANOVA for matched data. Both time and group variables had significant effects ( $p<0.0001$ for time and $p=0.0140$ for group). Tukey's multiple comparisons test showed no significant differences in all groups at week 0,2 , and 4 after immunization. At week 6 post immunization, the levels of IgG production in mice from $\mathrm{G} 1$ were significantly higher than those in the control groups $\mathrm{G} 4$, G5, and G6 ( $p<0.0001, p<0.0001$, and $p<0.0001$, respectively). The levels of IgG in G2 mice were significantly elevated compared with the control groups G4, G5, and G6 ( $p=0.0004, p=0.0004$, and $p=0.0003$, respectively). The levels of IgG in G3 mice were significantly high compared with the control groups G4, G5, and G6 ( $p=0.6142, p=0.5803$, and $p=0.5576$, respectively). The levels of IgG antibodies in mice from control groups (G4, G5, and G6) were not significantly different when compared with each other. Within G1, G2, and G3 groups, levels of IgG antibodies were not significantly different in G1 versus G2 $(p=0.8977)$, but were significantly different in G1 versus G3 $(p=0.0023)$ and in G2 versus G3 ( $p=0.0447)$.

The levels of IgG1 and IgG2a were determined 2 weeks after the final immunization. One-way ANOVA and Tukey's multiple comparisons test were used for statistical analysis of IgG1 and IgG2a data. The results of IgG1 analysis showed that G1 versus G4, G5, and G6 were all significantly different; G2 versus $\mathrm{G} 4(p=0.0626)$, G2 versus G5 $(p=0.0504), \mathrm{G} 2$ versus G6 $(p=0.0335)$, whereas G3 versus G4, G5, and G6 were not significant (Figure 2). The levels of IgG2a showed that G1 versus G4, G5, and G6 were all significant; G2 versus G4, G5, and G6 were all significant; and G3 versus G4 $(p=0.0765), \mathrm{G} 3$ versus G5 $(p=0.0053)$, and G3 versus G6 ( $p=0.0049)$. These results suggest that both IgG1 and 


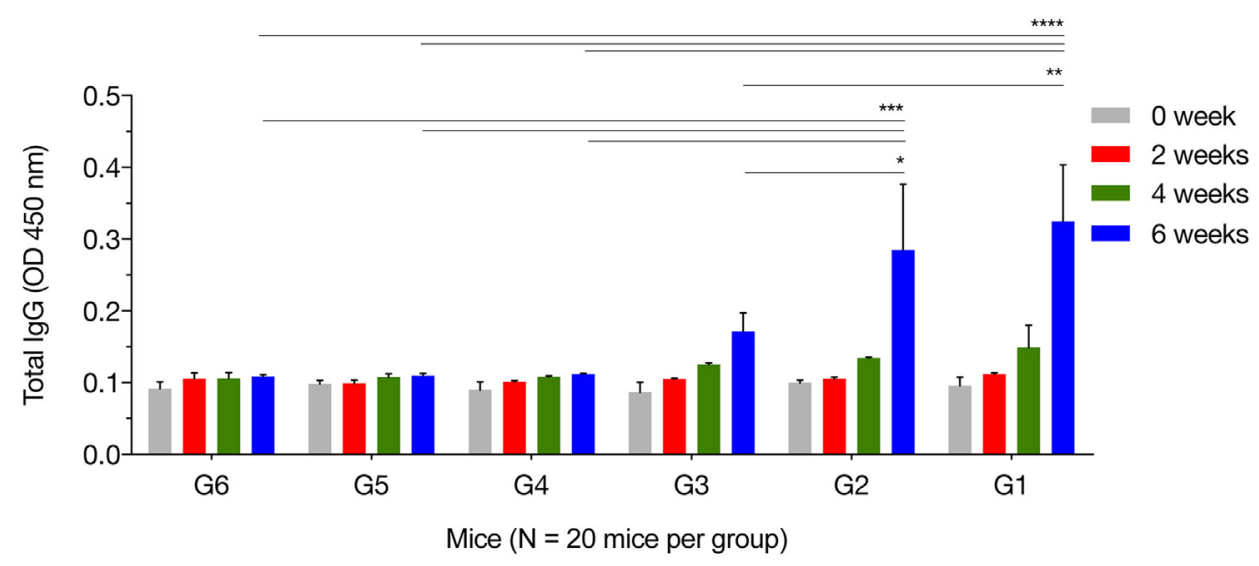

FIGURE 1 | Antigen-specific antibody response in immunized mice. Total lgG antibodies were determined in the sera of mice pre-immunization (0 week) and at 2, 4, and 6 weeks post three consecutive booster immunizations. Experimental groups include G1 mice received pVAX1 plasmids containing five antigens (ROP16, ROP18, MIC6, CDPK3, and PF); G2 mice received pVAX1 plasmids containing four antigens (ROP16, ROP18, MIC6, and CDPK3); G3 mice received pVAX1-PF; G4 mice received an empty pVAX1; G5 mice received phosphate-buffered saline alone; G6 healthy control mice. Data are mean \pm SDs for three wells (representative of three independent experiments). ${ }^{\star} p<0.05,{ }^{\star \star} p<0.01,{ }^{\star \star *} p<0.001$, and ${ }^{\star \star \star *} p<0.0001$, compared with the control groups.

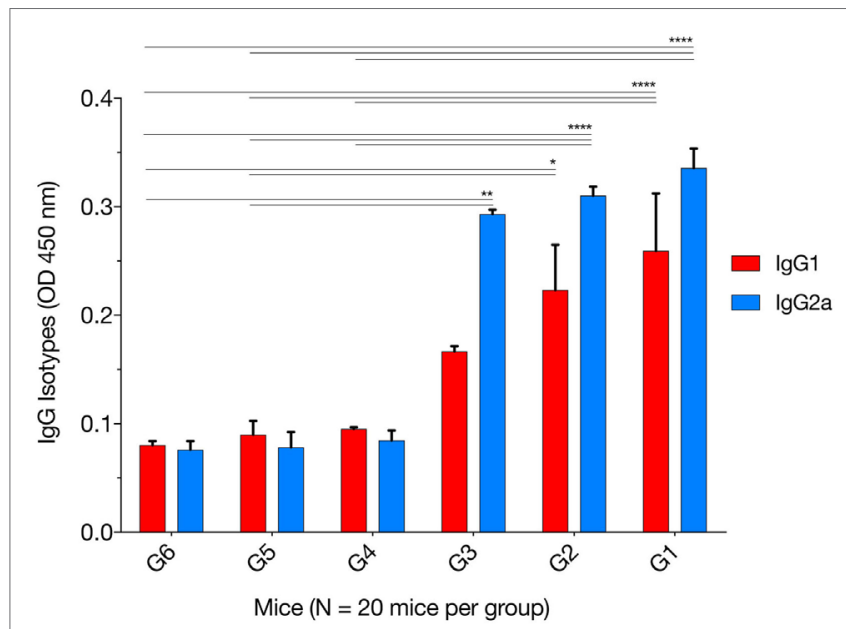

FIGURE 2 | Levels of IgG subclasses (IgG1 and lgG2a) in the sera of mice 2 weeks after the final booster immunization. The patterns of lgG2a to lgG1 post immunization using various immunization regimens suggest the induction of a mixed Th1/Th2 immune response. Experimental groups include G1: mice received pVAX1 plasmids containing five antigens (ROP16, ROP18, MIC6, CDPK3, and PF); G2: mice received pVAX1 plasmids containing four antigens (ROP16, ROP18, MIC6, and CDPK3); G3: mice received pVAX1-PF; G4: mice received an empty pVAX1; G5: mice received phosphate-buffered saline alone; G6: healthy control mice. Each bar represents the group $\mathrm{OD}_{450} \pm \mathrm{SDs}$ for three wells (representative of three experiments). ${ }^{*} p<0.05,{ }^{\star *} p<0.01$, and ${ }^{\star \star \star *} p<0.0001$, compared with the control groups.

IgG2a antibodies were higher in mice in G1, G2, and G3 than those in control groups at 2 weeks after the third immunization, suggesting a mixed Th1/Th2 immune response. To provide information on the dominant cellular immune type (Th1 or Th2) induced by immunization, ELISA was used to determine the ratio of IgG2a to IgG1 in the sera of all mouse groups. Results showed that immunized mouse groups, in particular, mice immunized with pVAX1-PF, had a slightly Th1-biased immune response as indicated by the higher IgG2a/IgG1 ratio (G1: 1.29; G2: 1.38; G3: 1.75) when compared with that of the control mouse groups (G4: 0.88; G5: 0.87; G6: 0.94; $p=0.0877$ ).

\section{Cellular Immune Responses}

The MTS assay was used to assess the T lymphocyte's proliferative response following stimulation with TLA or ConA. As expected, there was no difference for the SIs between the immunized groups (G1, G2, and G3). However, in vitro lymphocyte proliferation assay revealed that splenic lymphocytes from immunized mice had a significantly higher SI than their counterparts from nonimmunized controls, either in the presence of ConA or TLA extract. Exposure to $10 \mu \mathrm{g} / \mathrm{ml}$ TLA increased T-cell proliferation in G1, G2, and G3 compared with that obtained from control mice (Figure 3): G1 versus G6 ( $p=0.0010)$, G2 versus G6 ( $p=0.0012)$, and G3 versus G6 ( $p=0.0001)$. Similar results for T lymphocyte proliferation were obtained from splenocytes sensitized with $5 \mu \mathrm{g} / \mathrm{ml}$ TLA in mice from G1, G2, and G3 (Figure 3). The results of this ex vivo splenic lymphocyte proliferation assay suggested that immunization has induced antigen-specific lymphocyte proliferation.

We further characterized the cellular immune response, using flow cytometry analysis, and found that the numbers of $\mathrm{CD}^{+}$ $\mathrm{CD}^{+}{ }^{+} \mathrm{CD} 8^{-} \mathrm{T}$ cells in spleens of mice from G1, G2, and G3 were significantly higher than those from the controls (Figure 4). One-way ANOVA and Tukey's multiple comparisons test of the absolute numbers of $\mathrm{CD} 3^{+} \mathrm{CD} 4^{+} \mathrm{CD} 8^{-} \mathrm{T}$ cells in spleens, showed that $\mathrm{G} 1$ versus $\mathrm{G} 4(p=0.0010), \mathrm{G} 1$ versus $\mathrm{G} 5(p=0.0003), \mathrm{G} 1$ versus G6 ( $p=0.0005)$; G2 versus G4 $(p=0.0359)$, G2 versus G5 $(p=0.0130), \mathrm{G} 2$ versus G6 ( $p=0.0187)$; G3 versus G4 ( $p=0.0752)$, G3 versus G5 ( $p=0.0287)$, G3 versus G6 $(p=0.0407)$. After the third vaccination, mice immunized with various vaccines produced significantly higher $\mathrm{CD}^{+} \mathrm{CD}^{+} \mathrm{CD}^{-} \mathrm{T}$ cells in splenic 


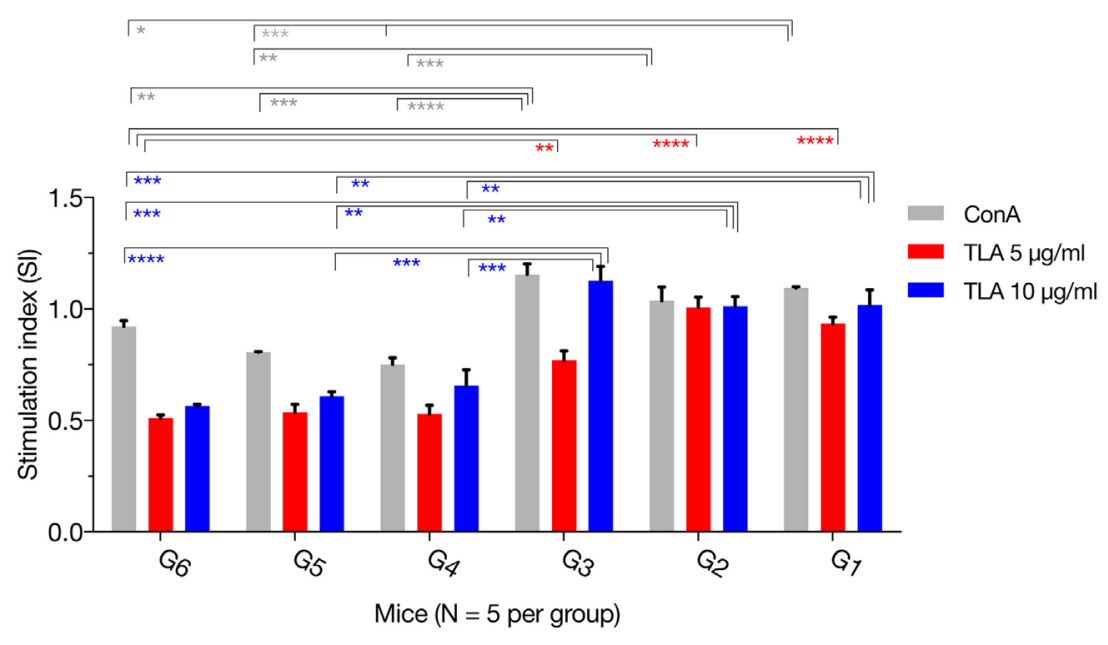

FIGURE 3 | In vitro lymphocyte proliferation induced by immunization. Splenocyte proliferation was assessed in mice 2 weeks after the final booster immunization. Exposure of splenocytes to 10 or $5 \mathrm{\mu g} / \mathrm{ml}$ T. gondii lysate antigen (TLA) significantly increased T cell proliferation in splenocytes obtained from mice in G1, G2, and G3, compared with proliferation in the control using antigen alone suggesting the induction of antigen-specific T-cell immune response after DNA immunization. Experimental groups include G1: mice received pVAX1 plasmids containing five antigens (ROP16, ROP18, MIC6, CDPK3, and PF); G2: mice received pVAX1 plasmids containing four antigens (ROP16, ROP18, MIC6, and CDPK3); G3: mice received pVAX1-PF; G4: mice received an empty pVAX1; G5: mice received phosphate-buffered saline alone; G6: healthy control mice. Each sample was assayed at least in triplicate. Data represent the mean \pm SD (error bars) from the five mice. ${ }^{*} p<0.05,{ }^{* *} p<0.01,{ }^{* \star *} p<0.001$, and ${ }^{* * *} p<0.0001$, compared with the control groups.

lymphocytes as did the controls. The numbers of $\mathrm{CD}^{+} \mathrm{CD}^{+}$ $\mathrm{CD}^{-} \mathrm{T}$ cells in mice from G1, G2, and G3 were significantly increased compared with those from control mice (Figure 4). One-way ANOVA and Tukey's multiple comparisons test of the absolute numbers of $\mathrm{CD}^{+}{ }^{+} \mathrm{CD} 8^{+} \mathrm{CD}^{-}$showed that $\mathrm{G} 1$ versus $\mathrm{G} 4$ $(p=0.0026), \mathrm{G} 1$ versus $\mathrm{G} 5(p=0.0038), \mathrm{G} 1$ versus $\mathrm{G} 6(p=0.0007)$; G2 versus G4 $(p=0.0381)$, G2 versus G5 $(p=0.0527)$, G2 versus G6 $(p=0.0111)$; G3 versus G4 $(p=0.0590)$, G3 versus G5 $(p=0.0804), \mathrm{G} 3$ versus $\mathrm{G} 6(p=0.0178)$. These findings suggest that the frequency of $\mathrm{CD} 4^{+} \mathrm{CD} 8^{+} \mathrm{T}$ cells were augmented after DNA immunization.

\section{Cytokine Production by Spleen Cells}

Following stimulation with TLA, significantly high levels of IFN- $\gamma$, IL-2, and IL-12 were observed in splenocyte cultures from mice in G1, G2, and G3 when compared with those from control mouse groups (Table 3). In regard to IL-2, G1, G2, and G3 were all significantly higher than G4, G5, and G6 (all $p<0.0001$ ). For IL-12, G1, G2, and G3 were all significantly higher than G4, G5, and G6 (all $p<0.0001$ ), and for IFN- $\gamma, \mathrm{G} 1, \mathrm{G} 2$, and G3 are all significantly higher than G4, G5, and G6 (all $p<0.001$ ). Levels of IL-4 in mice immunized with various DNA vaccines were not significantly different than those in mice from control groups $(p=0.5028)$. We analyzed the expression level of the transcription factors p65/RelA and T-bet using RT-PCR. We examined the difference between the expression of these two genes between control mice and mice in G1. Results showed that the expression of both p65/RelA and T-bet genes was significantly higher in G1 mice than in the control group $(p<0.0001$ and $p=0.0010)$ (Figure 5). This result indicates that p65/RelA and T-bet are induced by immunization and are likely to increase the production of IFN- $\gamma$ and IL-12 cytokines.

\section{Assessment of Protective Activity}

We evaluated which immunization regimen generated an immune response that was strong enough to protect against the formation of T. gondii brain cysts. Six mice from each group were challenged with 10 cysts of $T$. gondii Pru strain; and brain cyst loads were determined 6 weeks later. As shown in Figure 6, mice from G1, G2, and G3 had significantly lower numbers of brain cysts than those from control groups G4, G5, and G6 (all $p<0.0001$ ). The lowest number of brain cysts was detected in immunized mice from G1 $(643.33 \pm 89.63)$, which represented a significant reduction $(80.22 \%, p<0.0001)$ when compared with the number of cysts found in control non-immunized + challenged mice $(3,244.33 \pm 96.42)$. The number of brain cysts in G1 mice was significantly lower than in G2 or G3 mice $(p<0.0001)$.

\section{DISCUSSION}

Despite significant research to develop and evaluate anti- $T$. gondii vaccines, there is little consensus on the "best" antigens to target and the optimal means of targeting them. The development of vaccines to prevent cerebral toxoplasmosis disease in high risk populations could reduce the enormous tragedy associated with brain infection with cystogenic (brain cyst-forming) strains of T. gondii. A substantially reduced parasite cyst load in the brains of immunized mice in our study, together with enhanced humoral and cell-mediated immune responses-compared with non-immunized infected mice demonstrate that immunization with a DNA cocktail vaccine of five antigens, provides considerable protection in mice against a primary oral challenge with the avirulent cystogenic T. gondii Pru strain. These elements are believed to be important in developing an effective therapeutic vaccine. Our results showed that immunization using 

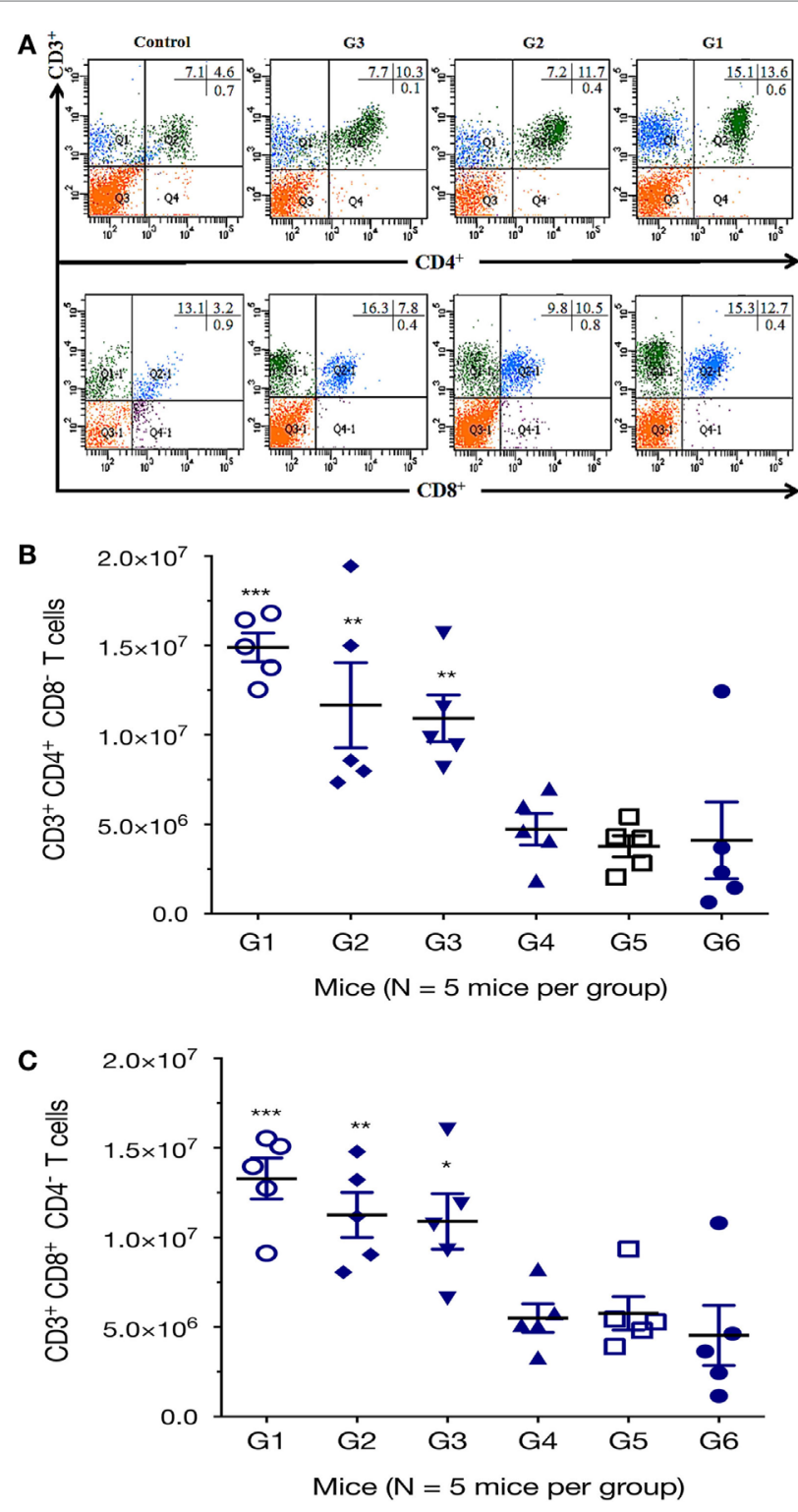

FIGURE 4 | DNA immunization augmented the frequency of antigen-specific T cells. Percentages of $\mathrm{CD}^{+}$and $\mathrm{CD}^{+} \mathrm{T}$ cells subsets were determined in the spleen of mice 2 weeks after the final immunization by flow cytometry analysis. (A) Representative dot plots showing the percentages of $\mathrm{CD}^{+}$ $\mathrm{CD}^{+}{ }^{+} \mathrm{CD} 8^{-}$and $\mathrm{CD}^{+}{ }^{+} \mathrm{CD} 8^{+} \mathrm{CD} 4^{-} \mathrm{T}$ lymphocytes. (B) Total numbers of CD3+ $\mathrm{CD}^{+}{ }^{+} \mathrm{CD} 8^{-} \mathrm{T}$ lymphocytes per spleen. (C) Total numbers of $\mathrm{CD}^{+} \mathrm{CD}^{+}$ CD4- T lymphocytes per spleen. Experimental groups include G1: mice received pVAX1 plasmids containing five antigens (ROP16, ROP18, MIC6, CDPK3, and PF); G2: mice received pVAX1 plasmids containing four antigens (ROP16, ROP18, MIC6, and CDPK3); G3: mice received pVAX1-PF; G4: mice received an empty pVAX1; G5: mice received phosphate-buffered saline alone; G6: healthy control mice. Data are mean \pm SDs (representative of three experiments). ${ }^{\star} p<0.05,{ }^{\star \star} p<0.01$, and ${ }^{\star \star \star} p<0.001$, compared with the control groups.

the cocktail DNA vaccine is a promising approach to control chronic toxoplasmosis, when compared with vaccination based on single antigens $(31-35)$. In this study, cocktail DNA vaccine achieved an $80.22 \%$ reduction in the parasite cyst burden, compared with $50 \%$ obtained by DNA vaccine expressing $T$. gondii CDPK3 (34) and $39.08 \%$ by DNA vaccine (pVAX1-PF) encoding TgPF gene (35). Reduction in the brain cysts' load achieved in our study, was also greater than the $57.8 \%$ reduction achieved by vaccination using multiple antigenic peptides encapsulated by chitosan microspheres (36).

The cytokine Th1 immune response is crucial for the control of infection with this obligate intracellular pathogen $(14,37)$. In our study, immunized mice developed a high level of antiT. gondii IgG antibodies, particularly after the third booster immunization. It is arguable that a high level of antibodies plays an important role in protection against subsequent infection with T. gondii tachyzoites, and in controlling T. gondii during chronic infection, by preventing cysts' reactivation. A requirement for $B$ cells, in addition to cell-mediated immunity, has been reported for mice challenged with virulent T. gondii parasites after vaccination with attenuated tachyzoitessuggesting that antibody-mediated immunity is also critical for T. gondii-induced protection (38). Our previous studies have demonstrated that the individual protective immunity offered by pVAX1-PF, pVAX1-ROP16, pVAX1-ROP18, pVAX1-MIC6, or pVAX1-CDPK3 against T. gondii infection, elicited a mixed Th1/Th2 or Th1-biased immunity via the induction of lymphocyte proliferation, activation of $\mathrm{CD}^{+}$ $\mathrm{T}$ cells and increased IFN- $\gamma$ production $(31-35)$. In this study, a mixed Th1/Th2 immune response, with a slight bias toward the Th1-type response, was detected in mice in groups G1, G2, and G3, as indicated by a slightly increased $\lg \mathrm{G} 2 \mathrm{a} / \mathrm{IgG} 1$ ratio (i.e., a higher level of IgG2a than IgG1). Vaccination using five antigens evoked an increase in $\mathrm{CD}^{+} \mathrm{T}$ lymphocytes and IFN- $\gamma$ production along with low levels of IL-4 in G1 mice compared with controls; all are characteristic features of a Th1-type cellular immune response. These findings indicate that a mixed Th1/Th2 protective immune response was elicited following immunization with the cocktail vaccine-consistent with the results of previous studies $(14,39)$.

A cellular immune response, including high levels of IFN- $\gamma$, $\mathrm{CD}^{+}$, and $\mathrm{CD}^{+} \mathrm{T}$ lymphocytes, is required for protection against chronic T. gondii infection (39-43). Both cell types act synergistically to control $T$. gondii infection, and effective control of $T$. gondii infection requires $\mathrm{CD}^{+}$for the generation of proficient $\mathrm{CD}^{+}$-mediated immunity (44). $\mathrm{CD}^{+} \mathrm{T}$ cells possess anti-cyst activity, mediated by a perforin-dependent mechanism $(45,46)$ and high levels of CD ${ }^{+} \mathrm{T}$ lymphocytes can contribute to a decrease of brain cyst loads $(39,43,47-50)$. In our study, the significantly increased numbers of $\mathrm{CD}^{+} \mathrm{T}$ cells in mice immunized with our cocktail vaccine may have contributed toward reducing the brain cyst burden.

Gamma-interferon, a crucial mediator of immune resistance to T. gondii infection, was detected in elevated levels in mice from G1, G2, and G3. IFN- $\gamma$ can activate macrophages and the CTL response during infection (51). Significantly higher expression of the transcription factor T-bet $(p=0.0010)$ was observed in mice in G1, compared with mice from the control group. This finding indicates that increased IFN- $\gamma$ production may have resulted from T-bet-mediated activation of $\mathrm{CD} 4^{+} \mathrm{T}$ cells and natural killer (NK) cells (36). In marked contrast with IFN- $\gamma$, the level 
TABLE 3 | Cytokine production by splenocytes of immunized Kunming mice after stimulation by T. gondii lysate antigen.

\begin{tabular}{|c|c|c|c|c|}
\hline \multirow[t]{2}{*}{ Group $^{b}$} & \multicolumn{4}{|c|}{ Cytokine production (pg/ml) } \\
\hline & Gamma-interferon & Interleukin-2 (IL-2) & IL-4 & Interleukin-12 (IL-12) \\
\hline G1 & $1,003.66 \pm 311.02$ & $294.24 \pm 11.1$ & $<10$ & $411.96 \pm 57.94$ \\
\hline G2 & $644.94 \pm 190$ & $269.35 \pm 19.17$ & $11.1 \pm 17.4$ & $184.75 \pm 39.95$ \\
\hline G3 & $1,930.26 \pm 5.46$ & $277.14 \pm 2.24$ & $<10$ & $400.14 \pm 54.43$ \\
\hline G4 & $169.29 \pm 1.66$ & $<50$ & $<10$ & $15.42 \pm 2.01$ \\
\hline G5 & $182.94 \pm 33.64$ & $<50$ & $<10$ & $<10$ \\
\hline G6 & $177.75 \pm 22.32$ & $<50$ & $<10$ & $<10$ \\
\hline
\end{tabular}

aNo significant difference ( $p>0.05$ ) in the level of the four cytokines was observed between the immunized groups (G1, G2, and G3) nor between the control groups (G4, G5, and G6). Differences between immunized groups and control groups were significant for INF- $\gamma(p<0.001)$, and for IL-2 and IL-12 ( $p<0.0001)$. Levels of IL-4 did not show any significant differences between the different mouse groups $(p>0.05)$.

${ }^{b}$ Experimental groups included G1: mice received pVAX1 plasmids containing five antigens (ROP16, ROP18, MIC6, CDPK3, and PF); G2: mice received pVAX1 plasmids containing four antigens (ROP16, ROP18, MIC6, and CDPK3); G3: mice received pVAX1-PF; G4: mice received an empty pVAX1; G5: mice received phosphate-buffered saline alone; G6: healthy control mice. Data are mean $\pm S D$ s for three wells (representative of three independent experiments).

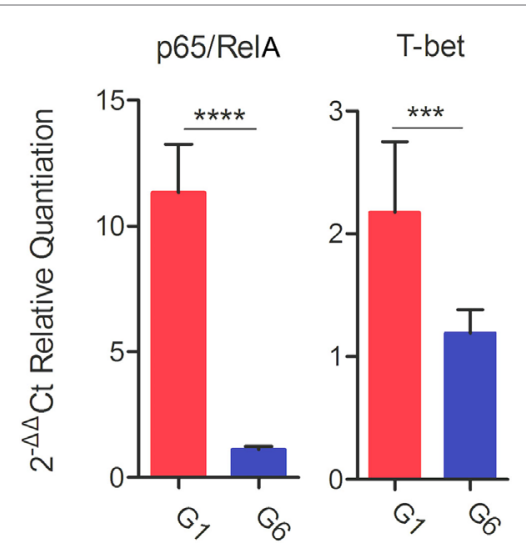

FIGURE 5 | Real-time-PCR expression analysis of the transcription factors p65/RelA and T-bet. $\beta$-Actin was used as a housekeeping reference gene. Experimental groups include G1: mice received pVAX1 plasmids containing five antigens (ROP16, ROP18, MIC6, CDPK3, and PF); G6: healthy control mice. Each sample was analyzed in triplicate. Data are mean \pm SDs (error bars) from the two mice. ${ }^{* \star *} p<0.001$ and ${ }^{* * * *} p<0.0001$.

of IL-4 was not statistically different between any mouse groups. IL-4 is a Th2-type cytokine, produced in response to receptor activation by Th2-type CD ${ }^{+} \mathrm{T}$ cells, basophils, and mast cells, and possesses B-cell stimulatory and Th2-promoting properties (52). IL-4 functions are generally antagonistic to those of IFN- $\gamma$, in line with the increased IFN- $\gamma$ and decreased IL-4 levels seen in our study. Elevated IFN- $\gamma$ production, together with a low level of IL-4, was also detected in mice immunized with DNA vaccines encoding TgROP1 (15), TgROM5 (39), TgCDPK2 (53), TgSAG1 (54), or multi-antigens $(17,19)$. IL-4 also promotes isotype-switching in murine B cells to IgG1 and IgE, but inhibits switching to IgG2a, IgG2b, and IgG3. This is in agreement with the reduced IL-4 and a high IgG2a to IgG1 ratio, observed in our study-providing more evidence of a biased Th1 type immune response.

Previous studies have shown that high levels of $\mathrm{CD}^{+}$and IL-2 production, increased mouse resistance to chronic toxoplasmosis $(30,41,42,55)$. We also found an increased production of $\mathrm{CD}^{+}$,

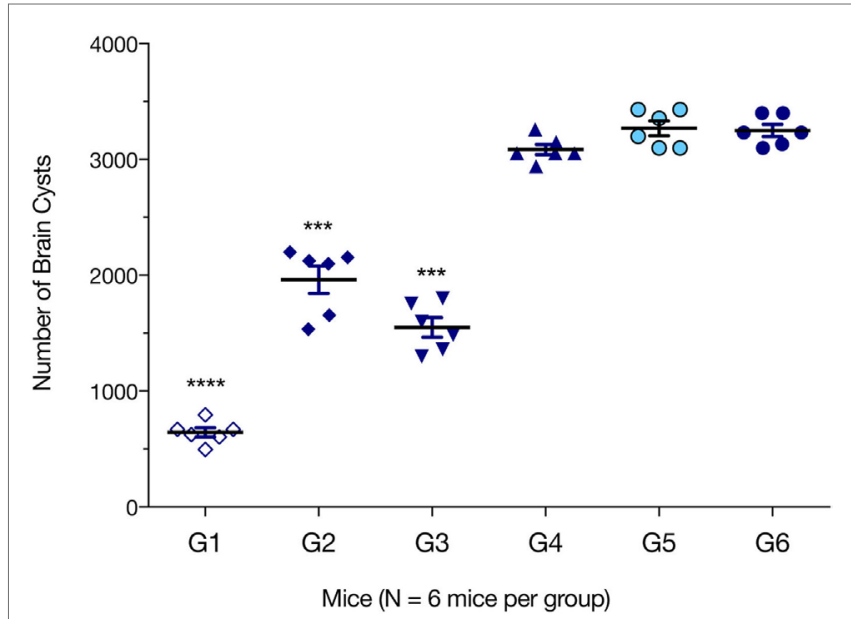

FIGURE 6 | Protection against chronic toxoplasmosis in immunized mice 2 weeks after the final booster immunization. Six mice per group were challenged orally with a dose of 10 cysts of the Pru strain (type II). Cyst load was counted from whole brain homogenates of mice 6 weeks after challenge. Experimental groups include G1: mice received pVAX1 plasmids containing five antigens (ROP16, ROP18, MIC6, CDPK3, and PF); G2: mice received pVAX1 plasmids containing four antigens (ROP16, ROP18, MIC6, and CDPK3); G3: mice received pVAX1-PF; G4: mice received an empty pVAX1; G5: mice received phosphate-buffered saline alone; G6: healthy control mice. Data are mean \pm SDs (representative of three experiments). ${ }^{* \star *} p<0.001$ and ${ }^{* \star *} p<0.0001$, compared with the control groups.

IL-2, and IL-12, along with a reduction in the brain cyst load in mice vaccinated with various DNA vaccines. A major role of NF- $\mathrm{KB}$ in resistance to T. gondii is the induction of IL-12 secretion (56). IL-12, putatively via STAT4, is important for the optimal production of INF- $\gamma$, which in turn induces differentiation of Th1 T lymphocytes, and possibly $\mathrm{CD}^{+}$and NK cells, to control T. gondii infection. Significantly increased expression of the transcription factor p65/RelA (a transcription factor of the $\mathrm{NF}-\kappa \mathrm{B}$ pathway) was observed in mice in G1, when compared with mice in the control group $(p<0.0001)$. This result, in addition to the increased level of IFN- $\gamma$, presents activation of NF- $\kappa \mathrm{B}$ pathway as an additional mechanism for increased IFN- $\gamma$ production to limit T. gondii infection. Suppressed 
expression of IL-12 resulted in 100\% mortality in mice infected with T. gondii (57). High levels of IL-12 contributed to brain cyst reduction in mice $(54,58)$. Toll-like receptor 11 (TLR11) signaling is an important pathway involved in the production of IL-12 $(23,59)$. T. gondii profilin (TgPF) can act as a ligand for TLR11 to mediate cytokine production (60-62) and has been exploited as a TLR-based vaccine adjuvant to enhance immune responses generated by vaccination (62-65). TgPF also plays an essential role in $T$. gondii gliding motility, invasion and egress from host cells $(23,24)$ and is an immunodominant antigen $(35,66)$. These key characteristics of TgPF prompted us to separately evaluate the protective efficacy of immunization with this gene against chronic toxoplasmosis. The specific finding that DNA vaccine encoding TgPF alone induced the production of high level of IL-12 is consistent with previous data (60) and, together with a higher IgG2a/IgG1 ratio and reduced brain cyst numbers may be of particular relevance. The enhanced protective immunity seen in mice from G1, compared with mice from group G2, suggests that TgPF may be necessary to augment the immune response induced by the multicomponent $T$. gondii DNA vaccine used in our study.

\section{CONCLUSION}

We have demonstrated that a strong humoral and cellular immune response, conferring significant protection against chronic T. gondii infection in mice-after immunization three times at 2-week intervals with a DNA vaccine encoding multiple antigens (TgPF, TgROP16, TgROP18, TgMIC6, and TgCDPK3). Several DNA immunizations were necessary to elicit the specific IgG antibody response. Immunization with several plasmids expressing more antigens produced a greater antibody response when compared with immunization using fewer plasmids expressing less number of antigens. These data support a call for further evaluation of multivalent synthetic plasmids as potential therapeutic T. gondii vaccines. Our findings are significant as they open up the possibility

\section{REFERENCES}

1. Montoya JG, Liesenfeld O. Toxoplasmosis. Lancet (2004) 363:1965-76. doi:10.1016/S0140-6736(04)16412-X

2. Robert-Gangneux F, Darde ML. Epidemiology of and diagnostic strategies for toxoplasmosis. Clin Microbiol Rev (2012) 25:264-96. doi:10.1128/ CMR.05013-11

3. Wohlfert EA, Blader IJ, Wilson EH. Brains and brawn: Toxoplasma infections of the central nervous system and skeletal muscle. Trends Parasitol (2017) 33:519-31. doi:10.1016/j.pt.2017.04.001

4. Wang ZD, Liu HH, Ma ZX, Ma HY, Li ZY, Yang ZB, et al. Toxoplasma gondii infection in immunocompromised patients: a systematic review and meta-analysis. Front Microbiol (2017) 8:389. doi:10.3389/fmicb.2017.00389

5. Hill DE, Dubey JP. Toxoplasma gondii as a parasite in food: analysis and control. Microbiol Spectr (2016) 4:PFS-0011-2015. doi:10.1128/microbiolspec. PFS-0011-2015

6. Belluco S, Simonato G, Mancin M, Pietrobelli M, Ricci A. Toxoplasma gondii infection and food consumption: a systematic review and meta-analysis of case-controlled studies. Crit Rev Food Sci Nutr (2017) 11:1-12. doi:10.1080/ 10408398.2017.1352563

7. Pan M, Lyu C, Zhao J, Shen B. Sixty years (1957-2017) of research on toxoplasmosis in China-an overview. Front Microbiol (2017) 8:1825. doi:10.3389/ fmicb.2017.01825 that chronic toxoplasmosis can be controlled by the combined action of multiple parasite-derived antigens. Although further studies and clinical evaluations are required, this study puts into place a "proof of concept" that tests the efficacy of the combination of a range of $T$. gondii antigens in preventing a chronic brain infection that is incurable with current therapeutics.

\section{ETHICS STATEMENT}

All animal protocols were reviewed and approved by the Animal Administration and Ethics Committee of Lanzhou Veterinary Research Institute, Chinese Academy of Agricultural Sciences. The study was performed in strict compliance with the recommendations set forth in the Animal Ethics Procedures and Guidelines of the People's Republic of China. All efforts were made to minimize animal suffering and to reduce the numbers of animals used in the experiments.

\section{AUTHOR CONTRIBUTIONS}

$\mathrm{X}-\mathrm{QZ}, \mathrm{N}-\mathrm{ZZ}$, and HE designed the experiments, interpreted the data, and critically revised the manuscript. N-ZZ, QG, MW, BW, and J-LW performed the experiments and analyzed the data. $\mathrm{N}-\mathrm{ZZ}$ drafted the manuscript. F-KZ, MW, and L-YH helped in the implementation of the study. All the authors reviewed and approved the final version of the manuscript.

\section{FUNDING}

Project support was provided by the National Key Research and Development Program of China (Grant no. 2017YFD0501304), by the National Natural Science Foundation of China (Grant no. 31602045), by the Elite Program of Chinese Academy of Agricultural Sciences, and by the Agricultural Science and Technology Innovation Program (ASTIP) (Grant No. CAAS-ASTIP-2016-LVRI-03).
8. Alday PH, Doggett JS. Drugs in development for toxoplasmosis: advances, challenges, and current status. Drug Des Devel Ther (2017) 11:273-93. doi:10.2147/DDDT.S60973

9. Zhang NZ, Chen J, Wang M, Petersen E, Zhu XQ. Vaccines against Toxoplasma gondii: new developments and perspectives. Expert Rev Vaccines (2013) 12:1287-99. doi:10.1586/14760584.2013.844652

10. Vercruysse J, Knox DP, Schetters TP, Willadsen P. Veterinary parasitic vaccines: pitfalls and future directions. Trends Parasitol (2004) 20:488-92. doi:10.1016/j. pt.2004.07.009

11. Robinson HL. DNA vaccines: basic mechanism and immune responses (review). Int J Mol Med (1999) 4:549-55.

12. Gurunathan S, Wu CY, Freidag BL, Seder RA. DNA vaccines: a key for inducing long-term cellular immunity. Curr Opin Immunol (2000) 12:442-7. doi:10.1016/S0952-7915(00)00118-7

13. Chen J, Huang SY, Li ZY, Yuan ZG, Zhou DH, Petersen E, et al. Protective immunity induced by a DNA vaccine expressing eIF4A of Toxoplasma gondii against acute toxoplasmosis in mice. Vaccine (2013) 31:1734-9. doi:10.1016/j. vaccine.2013.01.027

14. Zhang NZ, Wang M, Xu Y, Petersen E, Zhu XQ. Recent advances in developing vaccines against Toxoplasma gondii: an update. Expert Rev Vaccines (2015) 14:1609-21. doi:10.1586/14760584.2015.1098539

15. Sonaimuthu P, Ching XT, Fong MY, Kalyanasundaram R, Lau YL. Induction of protective immunity against toxoplasmosis in BALB/c mice vaccinated 
with Toxoplasma gondii rhoptry-1. Front Microbiol (2016) 7:808. doi:10.3389/ fmicb.2016.00808

16. Jongert E, Melkebeekd V, De Craeyeb S, Dewitc J, Verhelst D, Coxd E. An enhanced GRA1-GRA7 cocktail DNA vaccine primes anti-Toxoplasma immune responses in pigs. Vaccine (2008) 26:1025-31. doi:10.1016/j.vaccine. 2007.11.058

17. Fang R, Feng H, Hu M, Khan MK, Wang L, Zhou Y, et al. Evaluation of immune responses induced by SAG1 and MIC3 vaccine cocktails against Toxoplasma gondii. Vet Parasitol (2012) 187:140-6. doi:10.1016/j.vetpar.2011.12.007

18. Mévélec MN, Bout D, Desolme B, Marchand H, Magné R, Bruneel O, et al. Evaluation of protective effect of DNA vaccination with genes encoding antigens GRA4 and SAG1 associated with GM-CSF plasmid, against acute, chronical and congenital toxoplasmosis in mice. Vaccine (2005) 23:4489-99. doi:10.1016/j.vaccine.2005.04.025

19. Hoseinian Khosroshahi K, Ghaffarifar F, D'Souza S, Sharifi Z, Dalimi A. Evaluation of the immune response induced by DNA vaccine cocktail expressing complete SAG1 and ROP2 genes against toxoplasmosis. Vaccine (2011) 29:778-83. doi:10.1016/j.vaccine.2010.11.012

20. Beghetto E, Nielsen HV, Del Porto P, Buffolano W, Guglietta S, Felici F, et al. A combination of antigenic regions of Toxoplasma gondii microneme proteins induces protective immunity against oral infection with parasite cysts. J Infect Dis (2005) 191:637-45. doi:10.1086/427660

21. Picchio MS, Sánchez VR, Arcon N, Soto AS, Perrone Sibilia M, Aldirico MLA, et al. Vaccine potential of antigen cocktails composed of recombinant Toxoplasma gondii TgPI-1, ROP2 and GRA4 proteins against chronic toxoplasmosis in C3H mice. Exp Parasitol (2018) 185:62-70. doi:10.1016/j.exppara. 2018.01.006

22. Zheng B, He A, Gan M, Li Z, He H, Zhan X. MIC6 associates with aldolase in host cell invasion by Toxoplasma gondii. Parasitol Res (2009) 105:441-5. doi:10.1007/s00436-009-1401-5

23. Plattner F, Yarovinsky F, Romero S, Didry D, Carlier MF, Sher A, et al. Toxoplasma profilin is essential for host cell invasion and TLR11-dependent induction of an Interleukin-12 response. Cell Host Microbe (2008) 3:77-87. doi:10.1016/j.chom.2008.01.001

24. Koblansky AA, Jankovic D, Oh H, Hieny S, Sungnak W, Mathur R, et al. Recognition of profilin by toll-like receptor 12 is critical for host resistance to Toxoplasma gondii. Immunity (2013) 38:119-30. doi:10.1016/j.immuni.2012. 09.016

25. McCoy JM, Whitehead L, van Dooren GG, Tonkin CJ. TgCDPK3 regulates calcium-dependent egress of Toxoplasma gondii from host cells. PLoS Pathog (2012) 8:1003066. doi:10.1371/journal.ppat.1003066

26. El Hajj H, Lebrun M, Arold ST, Vial H, Labesse G, Dubremetz JF. ROP18 is a rhoptry kinase controlling the intracellular proliferation of Toxoplasma gondii. PLoS Pathog (2007) 3:e14. doi:10.1371/journal.ppat.0030014

27. Jensen KD, Hu K, Whitmarsh RJ, Hassan MA, Julien L, Lu D, et al. Toxoplasma gondii rhoptry 16 kinase promotes host resistance to oral infection and intestinal inflammation only in the context of the dense granule protein GRA15. Infect Immun (2013) 81:2156-67. doi:10.1128/IAI.01185-12

28. Zhou CX, Zhou DH, Elsheikha HM, Zhao Y, Suo X, Zhu XQ. Metabolomic profiling of mice serum during toxoplasmosis progression using liquid chromatography-mass spectrometry. Sci Rep (2016) 6:19557. doi:10.1038/ srep19557

29. Bastos LM, Macêdo AG Jr, Silva MV, Santiago FM, Ramos EL, Santos FA, et al. Toxoplasma gondii-derived synthetic peptides containing B- and T-cell epitopes from GRA2 protein are able to enhance mice survival in a model of experimental toxoplasmosis. Front Cell Infect Microbiol (2016) 6:59. doi:10.3389/ fcimb.2016.00059

30. Wang JL, Elsheikha HM, Zhu WN, Chen K, Li TT, Yue DM, et al. Immunization with Toxoplasma gondii GRA17 deletion mutant induces partial protection and survival in challenged mice. Front Immunol (2017) 8:730. doi:10.3389/ fimmu.2017.00730

31. Peng GH, Yuan ZG, Zhou DH, He XH, Liu MM, Yan C, et al. Toxoplasma gondii microneme protein 6 (MIC6) is a potential vaccine candidate against toxoplasmosis in mice. Vaccine (2009) 27:6570-4. doi:10.1016/j.vaccine.2009.08.043

32. Yuan ZG, Zhang XX, Lin RQ, Petersen E, He S, Yu M, et al. Protective effect against toxoplasmosis in mice induced by DNA immunization with gene encoding Toxoplasma gondii ROP18. Vaccine (2011) 29:6614-9. doi:10.1016/j. vaccine.2011.06.110
33. Yuan ZG, Zhang XX, He XH, Petersen E, Zhou DH, He Y, et al. Protective immunity induced by Toxoplasma gondii rhoptry protein 16 against toxoplasmosis in mice. Clin Vaccine Immunol (2011) 18:119-24. doi:10.1128/CVI. 00312-10

34. Zhang NZ, Huang SY, Zhou DH, Chen J, Xu Y, Tian WP, et al. Protective immunity against Toxoplasma gondii induced by DNA immunization with the gene encoding a novel vaccine candidate: calcium-dependent protein kinase 3 . BMC Infect Dis (2013) 13:512. doi:10.1186/1471-2334-13-512

35. Gao Q, Zhang NZ, Zhang FK, Wang M, Hu LY, Zhu XQ. Immune response and protective effect against chronic Toxoplasma gondii infection induced by vaccination with a DNA vaccine encoding profilin. BMC Infect Dis (2017) 18:117. doi:10.1186/s12879-018-3022-Z

36. Guo J, Sun X, Yin H, Wang T, Li Y, Zhou C, et al. Chitosan microsphere used as an effective system to deliver a linked antigenic peptides vaccine protect mice against acute and chronic toxoplasmosis. Front Cell Infect Microbiol (2018) 8:163. doi:10.3389/fcimb.2018.00163

37. Ismael AB, Sekkai D, Collin C, Bout D, Mévélec MN. The MIC3 gene of Toxoplasma gondii is a novel potent vaccine candidate against toxoplasmosis. Infect Immun (2003) 71:6222-8. doi:10.1128/IAI.71.11.6222-6228.2003

38. Sayles PC, Gibson GW, Johnson LL. B cells are essential for vaccination-induced resistance to virulent Toxoplasma gondii. Infect Immun (2000) 68(3):1026-33. doi:10.1128/IAI.68.3.1026-1033.2000

39. Zhang NZ, Xu Y, Wang M, Petersen E, Chen J, Huang SY, et al. Protective efficacy of two novel DNA vaccines expressing Toxoplasma gondii rhomboid 4 and rhomboid 5 proteins against acute and chronic toxoplasmosis in mice. Expert Rev Vaccines (2015) 14:1289-97. doi:10.1586/14760584.2015.1061938

40. Gazzinelli RT, Hakim FT, Hieny S, Shearer GM, Sher A. Synergistic role of $\mathrm{CD} 4+$ and $\mathrm{CD} 8+\mathrm{T}$ lymphocytes in IFN-gamma production and protective immunity induced by an attenuated Toxoplasma gondii vaccine. J Immunol (1991) 146:286-92.

41. Jordan KA, Hunter CA. Regulation of CD8+ T cell responses to infection with parasitic protozoa. Exp Parasitol (2010) 126:318-25. doi:10.1016/j. exppara.2010.05.008

42. Gazzinelli R, Xu Y, Hieny S, Cheever A, Sher A. Simultaneous depletion of $\mathrm{CD} 4+$ and $\mathrm{CD} 8+\mathrm{T}$ lymphocytes is required to reactivate chronic infection with Toxoplasma gondii. J Immunol (1992) 149:175-80.

43. El Bissati K, Zhou Y, Paulillo SM, Raman SK, Karch CP, Roberts CW, et al. Protein nanovaccine confers robust immunity against Toxoplasma. NPJ Vaccines (2017) 2:24. doi:10.1038/s41541-017-0024-6

44. Casciotti C, Ely K, Williams M, Khan I. CD8+-T-cell immunity against Toxoplasma gondii can be induced but not maintained in mice lacking conventional CD4+ T cells. Infect Immun (2002) 70:434-43. doi:10.1128/ IAI.70.2.434-443.2002

45. Hakim FT, Gazzinelli RT, Denkers E, Hieny S, Shearer GM, Sher A. CD8+ $\mathrm{T}$ cells from mice vaccinated against Toxoplasma gondii are cytotoxic for parasite-infected or antigen-pulsed host cells. J Immunol (1991) 147:2310-6.

46. Suzuki Y, Sa Q, Gehman M, Ochiai E. Interferon-gamma- and perforinmediated immune responses for resistance against Toxoplasma gondii in the brain. Expert Rev Mol Med (2011) 13:e31. doi:10.1017/S1462399411002018

47. Xu Y, Zhang NZ, Tan QD, Chen J, Lu J, Xu QM, et al. Evaluation of immunoefficacy of a novel DNA vaccine encoding Toxoplasma gondii rhoptry protein 38 (TgROP38) against chronic toxoplasmosis in a murine model. BMC Infect Dis (2014) 14:525. doi:10.1186/1471-2334-14-525

48. Scorza T, D'Souza S, Laloup M, Dewit J, De Braekeleer J, Verschueren H, et al. A GRA1 DNA vaccine primes cytolytic $\mathrm{CD} 8(+) \mathrm{T}$ cells to control acute Toxoplasma gondii infection. Infect Immun (2003) 71:309-16. doi:10.1128/ IAI.71.1.309-316.2003

49. Zhou J, Wang L. SAG4 DNA and peptide vaccination provides partial protection against T. gondii infection in BALB/c mice. Front Microbiol (2017) 8:1733 doi:10.3389/fmicb.2017.01733

50. Landrith TA, Sureshchandra S, Rivera A, Jang JC, Rais M, Nair MG, et al. CD103+ CD8 T cells in the Toxoplasma-infected brain exhibit a tissue-resident memory transcriptional profile. Front Immunol (2017) 8:335. doi:10.3389/ fimmu.2017.00335

51. Bessieres MH, Swierczynski B, Cassaing S, Miedouge M, Olle P, Sequela JP, et al. Role of IFN-gamma, TNF-alpha, IL4 and IL10 in the regulation of experimental Toxoplasma gondii infection. J Eukaryot Microbiol (1997) 44:87S. doi:10.1111/j.1550-7408.1997.tb05800.x 
52. Bao Y, Cao X. The immune potential and immunopathology of cytokineproducing B cell subsets: a comprehensive review. J Autoimmun (2014) 55: 10-23. doi:10.1016/j.jaut.2014.04.001

53. Chen K, Wang JL, Huang SY, Yang WB, Zhu WN, Zhu XQ. Immune responses and protection after DNA vaccination against Toxoplasma gondii calciumdependent protein kinase 2 (TgCDPK2). Parasite (2017) 24:41. doi:10.1051/ parasite/2017045

54. Meng M, He S, Zhao G, Bai Y, Zhou H, Cong H, et al. Evaluation of protective immune responses induced by DNA vaccines encoding Toxoplasma gondii surface antigen 1 (SAG1) and 14-3-3 protein in BALB/c mice. Parasit Vectors (2012) 5:273. doi:10.1186/1756-3305-5-273

55. Hwang S, Cobb DA, Bhadra R, Youngblood B, Khan IA. Blimp-1-mediated CD4 T cell exhaustion causes CD8 T cell dysfunction during chronic toxoplasmosis. J Exp Med (2016) 213:1799-818. doi:10.1084/jem.20151995

56. Mason NJ, Artis D, Hunter CA. New lessons from old pathogens: what parasitic infections have taught us about the role of nuclear factor-kappaB in the regulation of immunity. Immunol Rev (2004) 201:48-56. doi:10.1111/j. 0105-2896.2004.00189.x

57. Gazzinelli RT, Wysocka M, Hayashi S, Denkers EY, Hieny S, Caspar P, et al. Parasite-induced IL-12 stimulates early IFN-gamma synthesis and resistance during acute infection with Toxoplasma gondii. J Immunol (1994) 153:2533-43.

58. Yang WB, Zhou DH, Zou Y, Chen K, Liu Q, Wang JL, et al. Vaccination with a DNA vaccine encoding Toxoplasma gondii ROP54 induces protective immunity against toxoplasmosis in mice. Acta Trop (2017) 176:427-42. doi:10.1016/j.actatropica.2017.09.007

59. Pifer R, Yarovinsky F. Innate responses to Toxoplasma gondii in mice and humans. Trends Parasitol (2011) 27:388-93. doi:10.1016/j.pt.2011.03.009

60. Yarovinsky F, Zhang D, Andersen JF, Bannenberg GL, Serhan CN, Hayden MS, et al. TLR11 activation of dendritic cells by a protozoan profilin-like protein. Science (2005) 308:1626-9. doi:10.1126/science.1109893
61. Denkers EY, Striepen B. Deploying parasite profilin on a mission of invasion and danger. Cell Host Microbe (2008) 3:61-3. doi:10.1016/j.chom.2008.01.003

62. Yarovinsky F, Hieny S, Sher A. Recognition of Toxoplasma gondii by TLR11 prevents parasite-induced immunopathology. JImmunol (2008) 181:8478-84. doi:10.4049/jimmunol.181.12.8478

63. Pyo KH, Lee YW, Lim SM, Shin EH. Immune adjuvant effect of a Toxoplasma gondii profilin-like protein in autologous whole-tumor-cell vaccination in mice. Oncotarget (2016) 7:74107-19. doi:10.18632/oncotarget.12316

64. Neal LM, Knoll LJ. Toxoplasma gondii profilin promotes recruitment of Ly6Chi CCR2+ inflammatory monocytes that can confer resistance to bacterial infection. PLoS Pathog (2014) 10:e1004203. doi:10.1371/journal.ppat.1004203

65. Hedhli D, Moiré N, Akbar H, Laurent F, Héraut B, Dimier-Poisson I, et al. The antigen-specific response to Toxoplasma gondii profilin, a TLR11/12 ligand depends on its intrinsic adjuvant properties. Med Microbiol Immunol (2016) 205:345-52. doi:10.1007/s00430-016-0452-3

66. Tanaka S, Kuroda Y, Ihara F, Nishimura M, Hiasa J, Kojima N, et al. Vaccination with profilin encapsulated in oligomannose-coated liposomes induces significant protective immunity against Toxoplasma gondii. Vaccine (2014) 32:1781-5. doi:10.1016/j.vaccine.2014.01.095

Conflict of Interest Statement: The authors declare that the research was conducted in the absence of any commercial or financial relationships that could be construed as a potential conflict of interest.

Copyright (c) 2018 Zhang, Gao, Wang, Elsheikha, Wang, Wang, Zhang, Hu and Zhu. This is an open-access article distributed under the terms of the Creative Commons Attribution License (CC BY). The use, distribution or reproduction in other forums is permitted, provided the original author(s) and the copyright owner are credited and that the original publication in this journal is cited, in accordance with accepted academic practice. No use, distribution or reproduction is permitted which does not comply with these terms. 